\title{
Strategies supporting the prevention and control of neglected tropical diseases during and beyond the COVID-19 pandemic
}

\author{
John P. Ehrenberg ${ }^{1,2^{*}} \mathbb{D}$, Xiao-Nong Zhou ${ }^{3,4}$, Gilberto Fontes ${ }^{5}$, Eliana M. M. Rocha ${ }^{5}$, Marcel Tanner ${ }^{6,7}$ and \\ Jürg Utzinger ${ }^{6,7}$
}

\begin{abstract}
Emerging and re-emerging zoonotic diseases represent a public health challenge of international concern. They include a large group of neglected tropical diseases (NTDs), many of which are of zoonotic nature. Coronavirus disease 2019 (COVID-19), another emerging zoonotic disease, has just increased the stakes exponentially. Most NTDs are subject to the impact of some of the very same human-related activities triggering other emerging and re-emerging diseases, including COVID-19, severe acute respiratory syndrome (SARS), bird flu and swine flu. It is conceivable that COVID-19 will exacerbate the NTDs, as it will divert much needed financial and human resources. There is considerable concern that recent progress achieved with control and elimination efforts will be reverted. Future potential strategies will need to reconsider the determinants of health in NTDs in order to galvanize efforts and come up with a comprehensive, well defined programme that will set the stage for an effective multi-sectorial approach. In this Commentary, we propose areas of potential synergies between the COVID-19 pandemic control efforts, other health and nonhealth sector initiatives and NTD control and elimination programmes.
\end{abstract}

Keywords: COVID-19, Emerging and re-emerging diseases, Multi-sectorial approaches, Neglected tropical diseases, Zoonotic diseases

\section{Background}

Humanity faces a series of public and global health issues. For instance, there is a wide range of emerging and re-emerging zoonotic diseases, which affect a large number of individuals worldwide [1]. Hence, these diseases should be an important component of the current public health agenda, as they represent a serious public health threat. Yet, this is not the case. Coronavirus disease 2019 (COVID-19), another emerging zoonosis [2], has just

\footnotetext{
* Correspondence: ehrenbej@gmail.com

${ }^{1}$ Avenida Cedro 9, \# 303, Cholul, Merida, Yucatan, Mexico

${ }^{2}$ Formerly World Health Organization, Regional Office for the Western Pacific, Manila, The Philippines

Full list of author information is available at the end of the article
}

increased the stakes exponentially [3]. The emergence of severe acute respiratory syndrome coronavirus 2 (SARSCoV-2), the causative agent of COVID-19, is thought to have originated from a bat reservoir. It is one of seven coronaviruses known to infect humans.

Emerging and re-emerging diseases share a number of determinant factors, one of which is particularly critical: the impact of human activities on the environment [4]. Anthropogenic climate change is the most prominent [5]. Yet, other determinants, such as armed conflicts and war, changing land-use patterns, migration, unprecedented levels of transferring people and goods, and social inequity are known to pose major threats to human health and well-being [6, 7]. The gap between the 
"haves" and "have-not" is increasing even within the new developing economies. Vulnerable populations throughout the world, such as ethnic minorities, not only have less access to health care but are also disproportionally affected by a wide range of neglected tropical diseases (NTDs) [8, 9]. COVID-19 is clearly illustrating the importance of tackling these determinants, as even the largest economies in the world, including the United States of America, the People's Republic of China and countries in Europe are not spared the consequences.

NTDs comprise an important group of bacterial, parasitic and viral diseases, many of which are of zoonotic nature. Yet, as their name suggests, they continue to be neglected by most of the affected countries' health agendas. Throughout the world, impoverished populations are heavily burdened with NTDs and often lack access to primary health services [10]. The NTDs that affect people living in vulnerable conditions create social and financial burdens, which threaten the individual and their communities [10]. In spite of notable progress in controlling or even eliminating some NTDs (e.g. dracunculiasis, human African trypanosomiasis, lymphatic filariasis and onchocerciasis), their importance in terms of disease burden remains considerable [11, 12]. Importantly though, NTDs remain for the most part underfunded and efforts to combat them rely on the good will of the private sector and philanthropy. For example, onchocerciasis elimination in the Americas relied on a successful partnership involving The Carter Center, Merck and endemic countries, among other partners, and the local communities [12]. COVID-19 threatens hard won gains in NTD control and elimination efforts.

We are just beginning to appreciate the enormous economic impact COVID-19 is having across the world. It is conceivable that the economic crisis will drag millions of yet more people into poverty. It is not hard to imagine what effect this will have on the large populations affected and at-risk of NTDs. Estimates of the combined burden of the very first list comprising only 13 NTDs, i.e. 56.6 million disability-adjusted life years (DALYs) exceeded that of malaria and tuberculosis and even approached that of human immunodeficiency virus/acquired immunodeficiency syndrome (HIV/AIDS) [13]. According to 2015, estimates of the population atrisk in the Western Pacific region (comprising 37 countries) stood at 200 million individuals for schistosomiasis alone [9]. All of these countries now face the imminent danger of the aftermath of COVID-19.

\section{What do COVID-19 and NTDs have in common?}

COVID-19 and most NTDs are characterized by complex life cycles of the aetiological agents, which might involve one or more hosts as well as one or more species of vectors. Many NTDs are considered zoonosis because they affect primarily animal hosts but can jump species and affect humans, often with increased virulence and pathogenicity. This jump is almost always related to human activities and their impact on the environment. The list of NTDs is long [13, 14]. Out of the currently 20 NTDs listed by the World Health Organization (WHO) [15], this Commentary highlights four zoonotic NTDs, in order to illustrate prevention and control challenges, which are likely to increase in face of the unfolding COVID-19 pandemic [14, 16] (Table 1). The four selected NTDs cause considerable morbidity, might even lead to death and all have a significant economic impact on the already impoverished populations they affect. We believe that the economic impact of COVID-19 on these populations will be severe and long lasting.

\section{Schistosomiasis}

WHO calls for an integrated control strategy to face up to the challenge of 230 million people affected by this infection worldwide, mostly in sub-Saharan Africa [17]. Snail control is an important component of the overall control strategy, yet it has been found to pose considerable challenges. This is especially true in areas such as in the People's Republic of China where schistosomiasis transmission persists as a zoonosis. Control and elimination in this country illustrates the complexity of some of the issues. The number of infected people was estimated to be 725,000 in 2005 [18]. Great progress has been achieved since then with infection rates dropping to $<0.001 \%$ in humans $[19,20]$. In spite of continuous efforts by the Ministry of Health and partners, focal transmission persists in the lake region as a result of infection in cattle and resilience of the snail intermediate host posing a major risk for more than 30 million people in the endemic areas of the People's Republic of China [21]. Unlike other schistosome species known to infect humans, Schistosoma japonicum is a true zoonotic organism, with a range of mammalian reservoirs, rendering control and elimination efforts difficult [22].

\section{Cystic echinococcosis}

Cystic echinococcosis continues to represent a public health problem, affecting mostly disadvantaged people in Africa, the Americas and Asia [23]. These infections represent a burden adding to the already precarious situation of those affected, mainly poor farmers and herders throughout the endemic areas. Human incidence rates can be as high as 50 per 100,000 person-years, and prevalence levels as high as $5-10 \%$ in endemic regions. In South America, prevalence rates in slaughterhouses livestock can vary from 20 to $95 \%$. For most countries in Africa only scarce data exist, if at all [24]. Nevertheless, it is conceivable that the combined burden posed by cystic echinococcosis and other infectious diseases affecting 


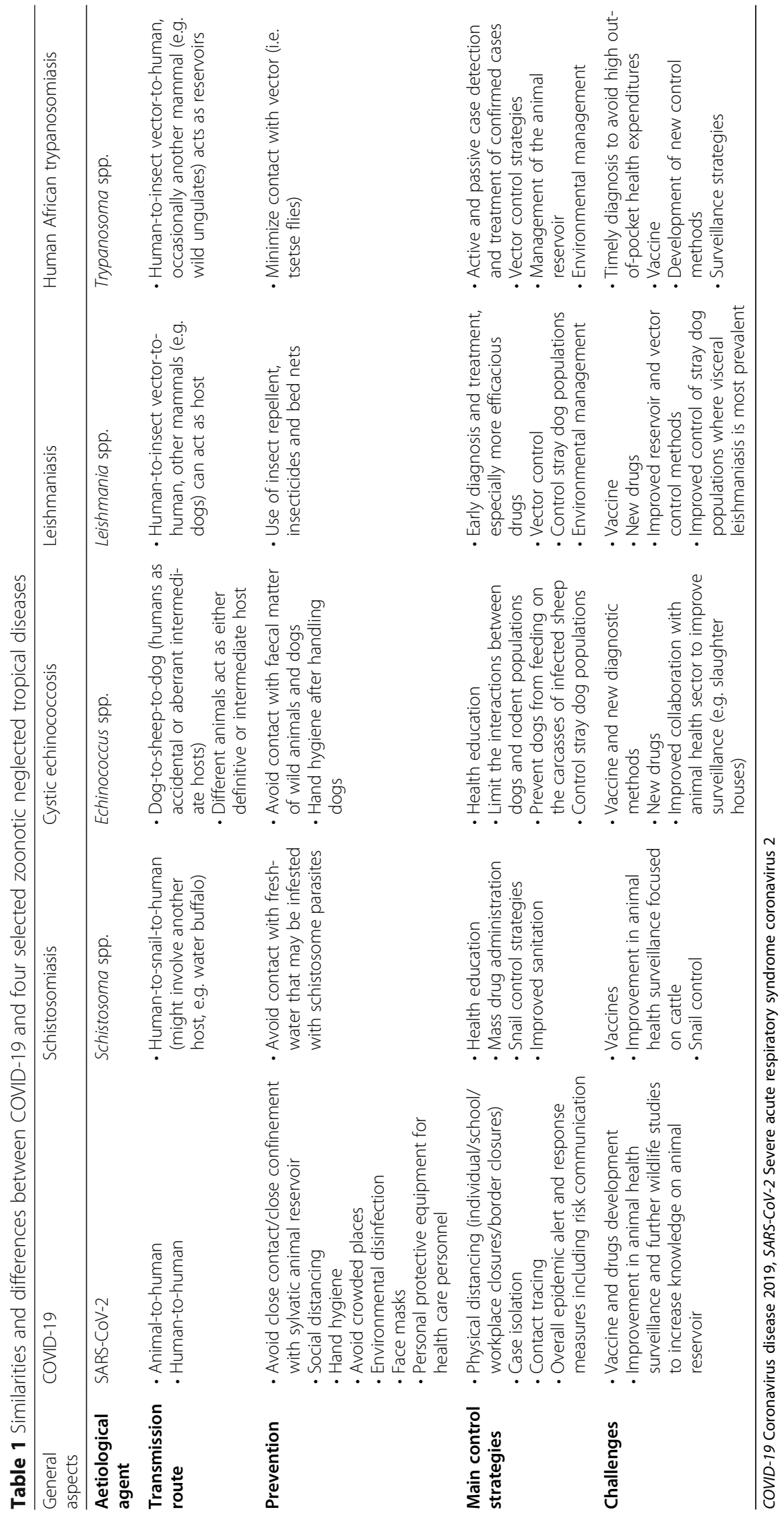


the very same population groups represents a major challenge to their health status and socioeconomic development. The paucity of effective tools to treat and prevent these infections represent a persistent obstacle illustrating the lack of interest by the relevant sectors in the development of new and efficacious drugs for many NTDs. It also highlights the lack of strategies, which could tap on the involvement of other sectors and key stakeholders behind a public health problem the determinants of which clearly reach well beyond the human health sector.

\section{Leishmaniasis}

Comprised of multiple species of causative agents, leishmaniasis are among the top ten NTDs with more than 12 million infected people throughout the Americas, Africa, Asia and the Middle East [25]. This complex includes a particularly worrisome species for its morbidity, visceral leishmaniasis (VL), with 200,000 to 400,000 new cases per year worldwide, and an estimate of 20,000 to 40,000 deaths per year [26].

In 2017, 20,792 out of 22,145 new cases (94\%) reported to WHO occurred in just seven countries; namely, Brazil, Ethiopia, India, Kenya, Somalia, South Sudan and Sudan [25, 27]. VL is prevalent in 12 countries in the Americas with 59,769 new cases reported from 2001 to 2017. Brazil accounts for $96 \%(57,582)$ of these cases [28]. The incidence rate of VL increased from 1990 to 2018 by $52.9 \%$ in this country alone with an even higher increase in children under the age of 1 year [28].

An additional challenge to effective control of this disease is canine visceral leishmaniasis (CVL), which constitutes a public health problem in some of the endemic countries. Cases of CVL are known to precede human cases of the disease, because dogs act as a reservoir. CVL plays an important role in the maintenance of transmission levels and the spread of the disease, particularly in urban areas [27, 29].

\section{Human African trypanosomiasis}

Human African trypanosomiasis control programmes throughout Africa have been successful, recording a decrease of cases during the period 2001-2010 of 73.4\% [30]. Yet, in spite of these impressive gains, delayed diagnosis of human African trypanosomiasis reported to have caused $93 \%$ of the affected households to experience an increase in financial expenditure (ranging from USD 60-170) in seeking treatment. To cover these outof-pocket health expenditures, $81.5 \%$ of the affected families experienced difficulties in raising money for treatment resorting to various ways of raising it such as selling agricultural produce, seeking assistance from family and friends, selling/leasing of family assets, seeking credit and/or using personal savings [31].

It is to be expected that COVID-19 will greatly contribute to the impoverishment of these populations seriously jeopardizing decades' long programmatic gains leading to a resurgence of human African trypanosomiasis.

\section{Challenges and recommendations: a case for a multi- sectoral strategy}

We are currently facing one of the most serious public health crises in decades, the COVID-19 pandemic [32]. Most NTDs are subject to the impact of some of the very same human-related activities triggering other emerging and re-emerging diseases, such as COVID-19, SARS, bird flu and swine flu. The exact life cycle of COVID-19's agent remains elusive to date [32]. The reason these epidemic-prone diseases attract more attention than the NTDs is that they can affect all, poor and rich, with extreme dire consequences in a short period of time. People can die within days of showing first symptoms. Just mentioning SARS or COVID-19 elicits a nervous response even from the financial sector. Economic losses have been consequently enormous. The key difference is NTDs affect primarily marginalized communities in low- and middle-income countries (LMICs), mainly rural and deprived urban communities. Economic losses, though significant, tend to be more selective in NTDs, affecting primarily the poor and medium income populations. While there is a frantic race among countries and pharmaceutical companies in COVID-19 for vaccines, drugs, diagnostics and protective gear, NTDs are not perceived as a lucrative market by the very same sectors hampering the development of diagnostics, drugs and vaccines.

COVID-19 could very well last for months, perhaps years. Unless we raise the profile of the NTDs, while the human population is highly sensitized to a public health crisis the likes of COVID-19, we might not get another opportunity to leverage on the raised awareness of emerging and re-emerging zoonotic diseases.

Health services and disease surveillance will need to undergo profound changes in order to find more effective ways of coping with emerging and re-emerging diseases in the future, zoonosis among these. The failure of most countries to respond adequately to COVID-19 makes a clear case for significant transformation of our systems. The NTD community would be well advised to jump on board. Integration of health and care services (e.g. group- and disease-specific models) [33] will need to be seriously considered in a post-COVID-19 world. It might also offer several potential venues to tackle morbidity in some NTDs. This issue deserves special attention, as it remains to be seen whether current integrated 
Table 2 Examples of where COVID-19 could synergize NTD efforts

\begin{tabular}{ll}
\hline Fields in mitigation & Opportunities for synergies with NTD control and elimination programmes \\
\hline $\begin{array}{l}\text { Overall surveillance capabilities strengthened in COVID-19 } \\
\text { including surveillance sentinel sites }\end{array}$ & May improve NTD surveillance \\
Political stakeholders & Leverage for increased involvement in NTDs \\
Private stakeholders & Leverage for increased involvement in NTDs \\
Risk communications developed for epidemic prone diseases & $\begin{array}{l}\text { May support greater community involvement and behavioural } \\
\text { changes in NTDs }\end{array}$ \\
Media information dissemination & Piggybacking opportunity for NTDs \\
IT capabilities strengthened in COVID-19 & Piggybacking opportunity for NTDS \\
Field logistics & Piggybacking opportunity for NTDs
\end{tabular}

COVID-19 Coronavirus disease 2019, NTDs Neglected tropical diseases, IT Information Technology

Table 3 Examples of where other health and non-health sectors (private, public and not-for-profit) could synergize NTD efforts

\begin{tabular}{|c|c|}
\hline Sector & Opportunities for synergies \\
\hline \multirow[t]{3}{*}{ Veterinary } & - Disease surveillance (clinical and laboratory) \\
\hline & - Field related logistics \\
\hline & - One Health initiative \\
\hline \multirow[t]{4}{*}{ Policy } & • Legislation \\
\hline & - Assigning and/or increasing programme budgets \\
\hline & - Streamlining financial flows to support effective supply chains \\
\hline & $\begin{array}{l}\text { - Implement strategies to promote economic development of affected populations (e.g. micro enterprises, } \\
\text { revolving funds, etc.) }\end{array}$ \\
\hline Economic & - Cost and feasibility studies \\
\hline Marketing & - Tap on private sector expertise and adapt to use in health programmes \\
\hline Communication & - Adapt private and public sector strategies \\
\hline Pharmaceutical & $\begin{array}{l}\text { - In conjunction with national academia and other organizations (e.g. Drugs for Neglected Diseases initiative } \\
\text { (DNDi)), support development of new drugs and diagnostics }\end{array}$ \\
\hline Environmental & $\begin{array}{l}\text { - Programmes targeting sustainable environment protection actions to prevent severe environmental } \\
\text { degradation in NTD areas }\end{array}$ \\
\hline \multirow[t]{4}{*}{ Information Technology (IT) } & - Integrated information systems \\
\hline & - Access to inter-sectoral data bases \\
\hline & - Geographic information systems \\
\hline & - New surveillance systems \\
\hline Transportation & - Private companies (e.g. beverage sector) support public health interventions \\
\hline \multirow[t]{3}{*}{ Malaria, tuberculosis and HIV/AIDS } & - Include NTDs in a repackaging of public health interventions \\
\hline & - Malaria, tuberculosis and HIV/AIDS benefit from integrated synergies \\
\hline & - NTDs benefit from high media profile of the three big ones \\
\hline \multirow[t]{5}{*}{ Agriculture } & - Encourage community development in NTD endemic areas by \\
\hline & - enabling local produce and self-sufficiency; \\
\hline & - organic farming; \\
\hline & - assistance in placing produce in markets; and \\
\hline & - One Health initiative \\
\hline \multirow[t]{3}{*}{ Education } & - Access to rural and marginalized population groups \\
\hline & - Sensitizing in health and environment topics \\
\hline & - Incorporating health into educational messages and curricula \\
\hline Anthropology & - Provide tools to enable integration of local cultural patterns into public health programmes \\
\hline Psychology & $\begin{array}{l}\text { - Integrated mental health programmes relying on ethical and culturally sensitive tools supporting vulnerable } \\
\text { populations }\end{array}$ \\
\hline \multirow[t]{2}{*}{ Development } & - Poverty alleviation programmes \\
\hline & - Capacity building in income generating activities \\
\hline
\end{tabular}


health care models could be extrapolated to NTDs in settings of LMICs.

An example of how non-health sector programme activities could be articulated with elements of NTD helminth control programme activities is described in a comprehensive analysis conducted in 2015. The analysis renders an interesting scenario, which should be further explored [9]. The One Health initiative is a movement to forge co-equal, all inclusive collaborations between physicians, osteopathic physicians, veterinarians, dentists, nurses and other scientific-health and environmentally related disciplines. However, it needs to ensure that other relevant sectors are included in the discussions of methodologies, definition of indicators and in the actual implementation of multicentre pilot studies to determine feasibility of multi-sectoral strategies. Given the uniqueness of each setting, meaning countries and continents, potential synergies with COVID-19 public health interventions (Table 2) and other sectors (Table 3) agendas would need to be tested and adapted to each particular social-ecological setting.

\section{Conclusions}

We believe that COVID-19 will exacerbate the NTD situation, as it will divert much needed financial and human resources. One might even anticipate a reversal in progress achieved in some of the NTD control and elimination efforts, similar to what is predicted for child and maternal health, malaria, tuberculosis and HIV/AIDS [34, 35]. Public health services are being stretched to their limits by COVID-19 and will continue to be so for some time to come. Other public health programmes will most likely suffer the consequences across the board. This will force the medical and the political establishments to make some extremely tough choices. We conjecture that COVID-19 will push a large proportion of the human population into poverty, even extreme poverty. To the NTD community, while we do face this rather dire scenario, it is imperative that we find alternative strategies if we want to retain the gains of NTD control and elimination programmes.

Future potential strategies will need to reconsider the determinants of health in NTDs in order to galvanize efforts and come up with comprehensive, well defined programmes that will set the stage for a multi-sectorial approach involving the medical, animal and human, developmental, environmental, agricultural, education, economy, anthropology, communications, public, private sectors, bilateral agencies and information technology sectors.

\section{Abbreviations}

COVID-19: Coronavirus disease 2019; DALY: Disability-adjusted life year; GSK: Glaxo-Smith-Klein; HIV/AIDS: Human immunodeficiency virus/acquired immunodeficiency syndrome; IT: Information Technology; LMICs: Low- and middle-income countries; NTDs: Neglected tropical diseases; SARS: Severe acute respiratory syndrome; SARS-CoV-2: Severe acute respiratory syndrome coronavirus 2; WHO: World Health Organization

\section{Acknowledgements}

We thank Nieves Ehrenberg for her proofreading, commenting and correcting typos. We thank anonymous reviewers for providing useful comments and suggestions to improve the manuscript.

\section{Availability of supporting data}

Not applicable.

\section{Authors' contributions \\ JPE conceived idea of paper and wrote first draft; GF and EMMR worked on all subsequent drafts and references; $J U$ and XNZ proposed tables and provided first format; $J U$ and MT revised the paper. All authors read and approved the final manuscript.}

\section{Funding}

Not applicable.

\section{Availability of data and materials}

Not applicable.

Ethics approval and consent to participate

Not applicable.

Consent for publication

Not applicable.

\section{Competing interests}

The authors declare that they have no competing interests. XNZ is the Editor-in-Chief of Infectious Diseases of Poverty. JPE is retired Director of Combating Communicable Diseases at Regional Office for the Western Pacific, WHO; XNZ was a former member of Strategic and Technical Advisory Group on Neglected Tropical Diseases, WHO.

\section{Author details}

${ }^{1}$ Avenida Cedro 9, \# 303, Cholul, Merida, Yucatan, Mexico. ${ }^{2}$ Formerly World Health Organization, Regional Office for the Western Pacific, Manila, The Philippines. ${ }^{3}$ National Institute of Parasitic Diseases at the Chinese Center for Disease Control and Prevention \& Chinese Center for Tropical Diseases Research, Shanghai, People's Republic of China. ${ }^{4}$ School of Global Health, Chinese Center for Tropical Diseases Research - Shanghai Jiao Tong University School of Medicine, Shanghai, People's Republic of China. ${ }^{5}$ Laboratory of Parasitology, Central-West Campus, Federal University of São João del Rei, Divinopolis, Minas Gerais, Brazil. ${ }^{6}$ Swiss Tropical and Public Health Institute, Basel, Switzerland. University of Basel, Basel, Switzerland.

Received: 4 June 2020 Accepted: 15 June 2020

Published online: 10 July 2020

\section{References}

1. Jones KE, Patel NG, Levy MA, Storeygard A, Balk D, Gittleman JL, et al. Global trends in emerging infectious diseases. Nature. 2008;451:990-3. https://doi.org/10.1038/nature06536.

2. Mackenzie JS, Smith DW. COVID-19: a novel zoonotic disease caused by a coronavirus from China: what we know and what we don't. Microbiol Aust. 2020;41:45-50. https://doi.org/10.1071/MA20013.

3. Helmy YA, Fawzy M, Elaswad A, Sobieh A, Kenney SP, Shehata AA. The COVID-19 pandemic: a comprehensive review of taxonomy, genetics, epidemiology, diagnosis, treatment, and control. J Clin Med. 2020;9:E1225. https://doi.org/10.3390/jcm9041225

4. Brower JL. The threat and response to infectious diseases. Microb Ecol. 2018;76:19-36. https://doi.org/10.1007/s00248-016-0806-9.

5. El-Sayed A, Kamel M. Climatic changes and their role in emergence and reemergence of diseases. Environ Sci Pollut Res Int. 2020;27:22336-52. https:// doi.org/10.1007/s11356-020-08896-W.

6. Marmot M, Friel S, Bell R, Houweling TA, Taylor S. Closing the gap in a generation: health equity through action on the social determinants of health. Lancet. 2008:372:1661-9. https://doi.org/10.1016/S01406736(08)61690-6. 
7. GBD 2017 DALYs and HALE Collaborators. Global, regional, and national disability-adjusted life-years (DALYs) for 359 diseases and injuries and healthy life expectancy (HALE) for 195 countries and territories, 1990-2017: a systematic analysis for the Global Burden of Disease Study 2017. Lancet. 2018;392:1859-922. https://doi.org/10.1016/S0140-6736(18)32335-3.

8. Schratz A, Pineda MF, Reforma LG, Fox NM, Le Anh T, Tommaso CavalliSforza L, et al. Neglected diseases and ethnic minorities in the Western Pacific region: exploring the links. Adv Parasitol. 2010;72:79-107. https://doi. org/10.1016/S0065-308X(10)72004-2.

9. Nakagawa J, Ehrenberg JP, Nealon J, Fürst T, Aratchige P, Gonzales G, et al. Towards effective prevention and control of helminth neglected tropical diseases in the Western Pacific region through multi-disease and multisectoral interventions. Acta Trop. 2015;141:407-18. https://doi.org/10.1016/j. actatropica.2013.05.010.

10. Ehrenberg JP, Ault SK. Neglected diseases of neglected populations: thinking to reshape the determinants of health in Latin America and the Caribbean. BMC Public Health. 2005;5:119. https://doi.org/10.1186/14712458-5-119

11. Gyapong JO, Owusu IO, Vroom FBC, Mensah EO, Gyapong M. Elimination of lymphatic filariasis: current perspectives on mass drug administration. Res Rep Trop Med. 2018;9:25-33.

12. Sauerbrey M, Rakers LJ, Richards FO Jr. Progress toward elimination of onchocerciasis in the Americas. Int Health. 2018;10:171-8. https://doi.org/10. 1093/inthealth/ihx039.

13. Hotez PJ, Molyneux DH, Fenwick A, Ottesen E, Ehrlich Sachs S, Sachs JD. Incorporating a rapid-impact package for neglected tropical diseases with programs for HIV/AIDS, tuberculosis, and malaria. PLoS Med. 2006;3:e102. https://doi.org/10.1371/journal.pmed.0030102.

14. Utzinger J, Becker SL, Knopp S, Blum J, Neumayr AL, Keiser J, et al. Neglected tropical diseases: diagnosis, clinical management, treatment and control. Swiss Med Wkly. 2012;22(142):w13727. https://doi.org/10.4414/smw. 2012.13727.

15. World Health Organization. Neglected tropical diseases. https://www.who. int/neglected_diseases/diseases/en/. Accessed 25 May 2020.

16. Bodimeade C, Marks M, Mabey D. Neglected tropical diseases: elimination and eradication. Clin Med. 2019;19:157-60. https://doi.org/10.7861/ clinmedicine.19-2-157.

17. World Health Organization. Neglected tropical diseases. Schistosomiasis elimination: refocusing on snail control to sustain progress. https://www who.int/neglected_diseases/news/schisto-elimination-refocusing-snailcontrol-sustain-progress/en/. Accessed 25 May 2020.

18. Zhou XN, Guo JG, Wu XH, Jiang QW, Zheng J, Dang H, et al. Epidemiology of schistosomiasis in the People's Republic of China, 2004. Emerg Infect Dis. 2007;13:1470-6. https://doi.org/10.3201/eid1310.061423.

19. Zhang LJ, Xu ZM, Guo JY, Dai SM, Dang H, Lü S, et al. Endemic status of schistosomiasis in People's Republic of China in 2018. Chin J Schisto Control. 2019;31:576-8. https://doi.org/10.16250/j.32.1374.2019247.

20. Xu J, Li SZ, Zhang LJ, Bergquist R, Dang H, Wang Q, et al. Surveillance-based evidence: elimination of schistosomiasis as a public health problem in the People's Republic of China. Infect Dis Poverty. 2020;9:63.

21. Qian MB, Chen J, Bergquist R, Li ZJ, Li SZ, Xiao N, et al. Neglected tropical diseases in the People's Republic of China: progress towards elimination. Infect Dis Poverty. 2019;8:86. https://doi.org/10.1186/s40249-019-0599-4.

22. Ross AGP, Sleigh AC, Li Y, Davis GM, Williams GM, Jiang Z, et al. Schistosomiasis in the People's Republic of China: prospects and challenges for the 21st century. Clin Microbiol Rev. 2001;14:270-95. https://doi.org/10. $1128 / C M R$.

23. World Health Organization. Echinococcosis fact sheet. https://www.who.int/ news-room/fact-sheets/detail/echinococcosis. Accessed 05 May 2020.

24. Wahlers K, Menezes CN, Wong ML, Zeyhle E, Ahmed ME, Ocaido M, et al. Cystic echinococcosis in sub-Saharan Africa. Lancet Infect Dis. 2012;12:87180. https://doi.org/10.1016/S1473-3099(12)70155-X.

25. World Health Organization. Leishmaniasis: epidemiological situation. https:// www.who.int/leishmaniasis/burden/en/. Accessed 27 Apr 2020.

26. Alvar J, Vélez ID, Bern C, Herrero M, Desjeux P, Cano J, et al. Leishmaniasis worldwide and global estimates of its incidence. PLoS One. 2012;7:e35671. https://doi.org/10.1371/journal.pone.0035671.

27. Wamai RG, Kahn J, McGloin J, Ziaggi G. Visceral leishmaniasis: a global overview. J Glob Health Sci. 2020;2:e3. https://doi.org/10.35500/jghs.2020.2.e3.

28. Bezerra JMT, Araujo VEM, Barbosa DS, Martins-Melo FR, Werneck GL, Carneiro M. Burden of leishmaniasis in Brazil and Federated Units, 1990-
2016: findings from Global Burden of Disease Study 2016. PLoS Negl Trop Dis. 2018;12:e0006697. https://doi.org/10.1371/journal.pntd.0006697 .

29. Vaz TP, Gama-Melo MO, Quaresma PF, Gontijo CMF, Barbosa FS, Fontes G. Evaluation of the euthanasia of seropositive dogs for canine visceral leishmaniasis as the only method of controling the disease in the enzootic area in the Midwestern Minas Gerais, Brazil. Pesqui Vet Bras. 2020;40:107-12. https://doi.org/10.1590/1678-5150-PVB-6165.

30. World Health Organization. Human African trypanosomiasis. The current situation. https://www.who.int/trypanosomiasis_african/country/country_ situation/en/ Accessed 05 May 2020.

31. Bukachi SA, Wandibba S, Nyamongo IK. The socio-economic burden of human African trypanosomiasis and the coping strategies of households in the South Western Kenya foci. PLoS Negl Trop Dis. 2017;e0006002. https:// doi.org/10.1371/journal.pntd.0006002

32. World Health Organization. Coronavirus disease (COVID-2019) situation reports. https://www.who.int/emergencies/diseases/novel-coronavirus-2019/ situation-reports. Accessed 27 Apr 2020.

33. World Health Organization. Integrated care models: an overview. Copenhagen: WHO Regional Office for Europe; 2016. p. 42.

34. Rahi M, Das P, Sharma A. Novel coronavirus disease (COVID-19) mitigation steps provide a blueprint for malaria control and elimination. Am J Trop Med Hyg. 2020;tpmd200394. https://doi.org/10.4269/ajtmh.20-0394.

35. Roberton T, Carter ED, Chou VB, Stegmuller AR, Jackson BD, Tam Y, et al. Early estimates of the indirect effects of the COVID-19 pandemic on maternal and child mortality in low-income and middle-income countries: a modeling study. Lancet Glob Health. 2020;8:e901-e908. https://doi.org/10. 1016/S2214-109X(20)30229-1.

\section{Ready to submit your research? Choose BMC and benefit from:}

- fast, convenient online submission

- thorough peer review by experienced researchers in your field

- rapid publication on acceptance

- support for research data, including large and complex data types

- gold Open Access which fosters wider collaboration and increased citations

- maximum visibility for your research: over $100 \mathrm{M}$ website views per year

At $\mathrm{BMC}$, research is always in progress.

Learn more biomedcentral.com/submissions 